\title{
The numb chin in breast cancer ${ }^{1}$
}

\author{
JOHN HORTON, EUGENE D. MEANS, T. J. CUNNINGHAM, \\ AND KENNETH B. OLSON
}

\begin{abstract}
From the Departments of Medicine (Division of Oncology) and Neurology, Albany Medical College, Albany, New York 12208 U.S.A.
\end{abstract}

SUMMARY Numbness of the chin, an uncommon neurological symptom, was observed in 15 patients with cancer. Thirteen had breast cancer. This symptom usually heralded progressive involvement of the cranial nerves or cerebrum and denoted a poor prognosis in patients with a short 'tumourfree interval'. The pathogenesis is commonly related to dural involvement of the Vth cranial nerve at the base of the brain, although metastasis to the mandible might sometimes be implicated. The reason for the peculiar predilection for the mandibular branch of the trigeminal nerve to be affected by breast cancer is not known.

Unilateral facial numbness is an uncommon primary symptom of neurological disease. It has been reported in association with multiple sclerosis (McAlpine, Lumsden, and Acheson, 1965), syphilis (Ornsteen, 1931), arachnoiditis (Hughes, 1958), sarcoidosis (Jefferson, 1957), connective tissue diseases (Ashworth and Tait, 1971), and after exposure to toxic chemicals (Collard and Hargreaves, 1947; Mitchell and Parsons-Smith, 1969). Trauma and dental abnormalities (Collard and Hargreaves, 1947) have caused the symptom and the relationship to space occupying lesions including primary nasopharyngeal cancer (New, 1922) and carotid aneurysm (Goldstein, Gibilisco, and Rushton, $1963)$ is well recognized. A benign sensory trigeminal neuropathy has also been described (Hill, 1954).

During the past five years we have seen 15 patients with a peculiar and distinctive symptom of numbness of the chin. Thirteen of these patients had breast cancer. The purpose of this report is to describe the clinical features of these patients, their progress, and the prognostic significance of this symptom.

\section{PATIENTS}

The patients included in this study were from a group of 2,000 patients with cancer, including 300 patients

1 Supported by Grant CAO6594 of the National Cancer Institute of the United States Public Health Service and the Manning Foundation. with breast cancer, seen by members of the Division of Oncology at the Albany Medical College during the last five years. All patients volunteered the symptom spontaneously without special questioning. The common complaint was of a unilateral sense of numbness occurring in the skin adjacent to the tip of the jaw. At times the area of numbness extended as far as the angle of the jaw. Pain was almost always absent but numbness of the subjacent mucous membrane occasionally occurred. The sensory deficit was confirmed by clinical examination. Studies performed on the patients usually included radiographs of the mandible and skull, lumbar puncture, electroencephalography, and, occasionally, $\mathrm{Hg}^{203}$ or Technetium brain scans.

The clinical features, associated findings, and outcome of the 15 patients are summarized in Table 1 . Thirteen patients $(86 \%)$ had breast cancer and two $(14 \%)$ lymphoma. All save one had metastatic disease at the time of presentation. The numb chin was the sole presenting neurological symptom in eight patients $(53 \%)$. Other cranial nerves or the maxillary branch of the trigeminal nerve were involved in four patients $(27 \%)$. Three patients $(20 \%)$ had paraplegia, two $(13 \%)$ proximal muscle weakness, and one had seizures.

Laboratory findings at the time of presentation of the neuropathy were of limited value. Radiographs of the skull showed evidence of metastatic involvement of the calvarium in seven patients. Careful study, even in retrospect, failed to reveal definite radiological evidence of bony defects in the region of the petrous temporal ridge. Figure 1 illustrates dural involvement of the base of the brain seen at necropsy 
of patient no. 3. No suggestion of this lesion was seen radiographically. Specific radiological studies of the mandible were performed on eight patients, although a less adequate view was obtained of the remainder from skull radiographs. Only two patients demonstrated mandibular metastasis. Figure 2 illustrates a radiograph of part of the mandible of patient no. 12. This shows extensive osteolysis. Lumbar puncture and electroencephalography were usually not helpful and abnormalities of brain scans performed reflected calvarial rather than intracerebral disease.

The clinical progression of the patients with breast cancer was quite variable. Five patients developed further cranial nerve involvement, two developed intracerebral metastasis, one had both posterior pituitary and intracerebral metastases, and one had a combination of posterior pituitary, intracerebral, and cranial nerve involvement. The neurological status remained unchanged in four patients but the survival of three of these patients was less than two months. One of the two patients with lymphoma had rapidly progressive cranial nerve dysfunction.

\section{TABLE 2}

CORRELATION OF SURVIVAL OF PATIENTS WITH BREAST CANCER FROM TIME OF ONSET OF NUMBNESS OF CHIN WITH DURATION OF TIME BETWEEN INITIAL DIAGNOSIS OF BREAST CANCER AND ONSET OF FIRST EVIDENCE OF METASTATIC DISEASE ('TUMOUR FREE INTERVAL')

\begin{tabular}{lccc}
\hline $\begin{array}{c}\text { Tumour free } \\
\text { interval } \\
\text { (yr) }\end{array}$ & $\begin{array}{c}\text { Median } \\
\text { survival } \\
\text { (months) }\end{array}$ & $\begin{array}{c}\text { Range } \\
\text { (months) }\end{array}$ & $\begin{array}{c}\text { Number of } \\
\text { patients }\end{array}$ \\
\hline Over 10 & $48+^{*}$ & Both 48+ & 2 \\
$5-10$ & 14 & - & 1 \\
$1-4$ & 5 & $2-24$ & 7 \\
Less than 1 & 2 & $\frac{1}{2}-4$ & 3 \\
\hline
\end{tabular}

* + signifies still alive.

Survival of the patients with breast cancer ranged from two weeks to over four years. There was little correlation between the type of progression of the neurological dysfunction and survival measured from the time of onset of mental numbness. A good correlation existed between the duration of the socalled 'disease free interval' and subsequent survival as shown in Table 2.

Treatment for the numb chin was not necessary as the symptom itself was trivial. Most patients received radiation and/or chemotherapy to control progres-

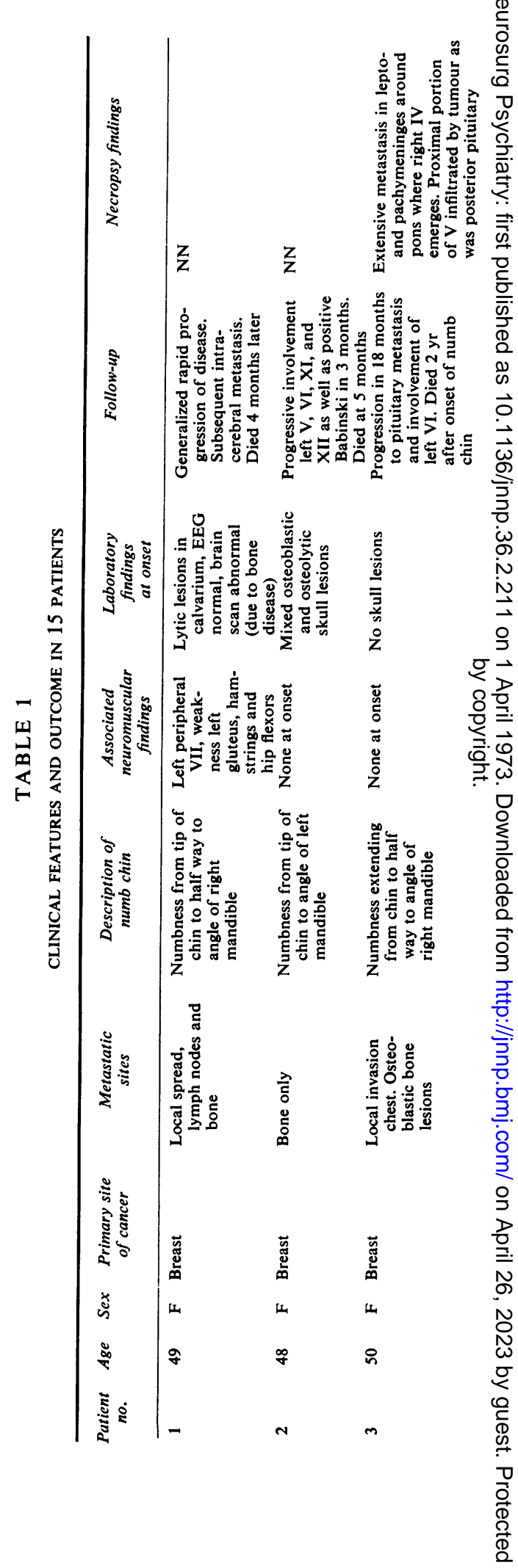



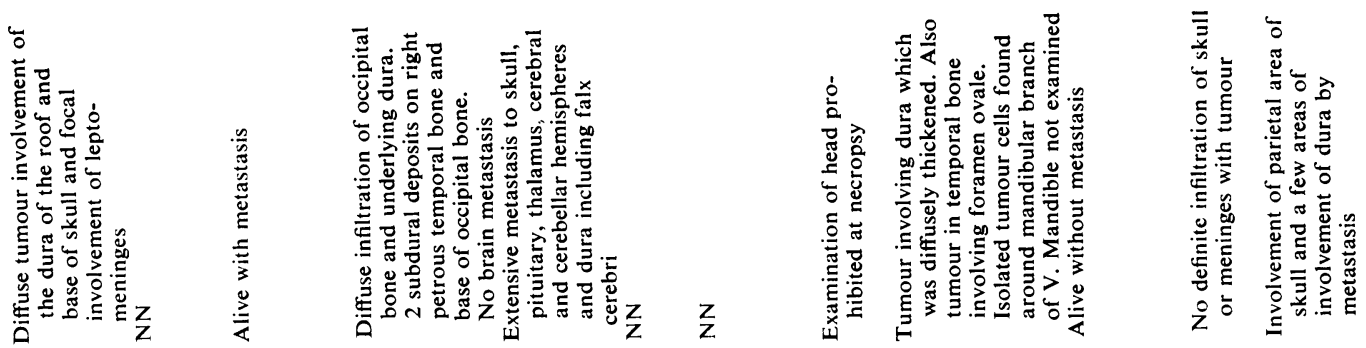

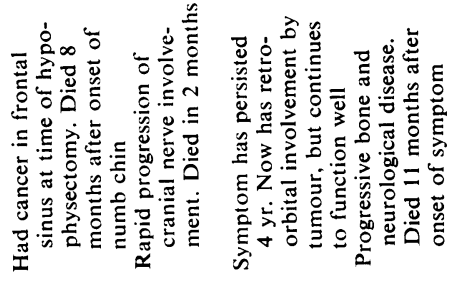

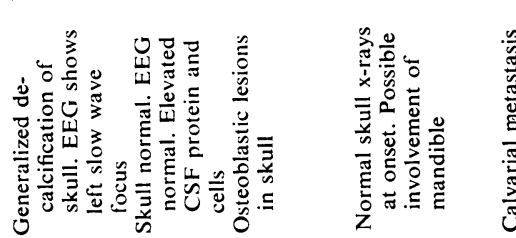

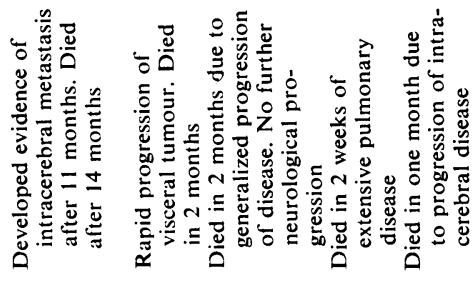

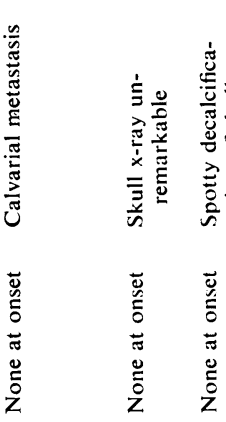

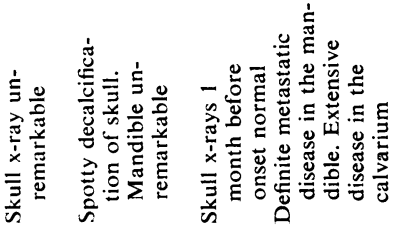

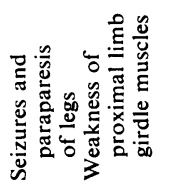

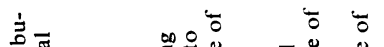

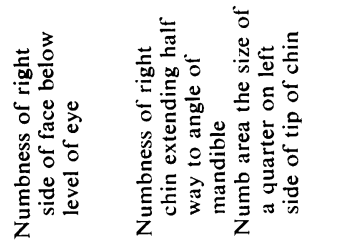

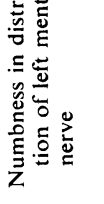

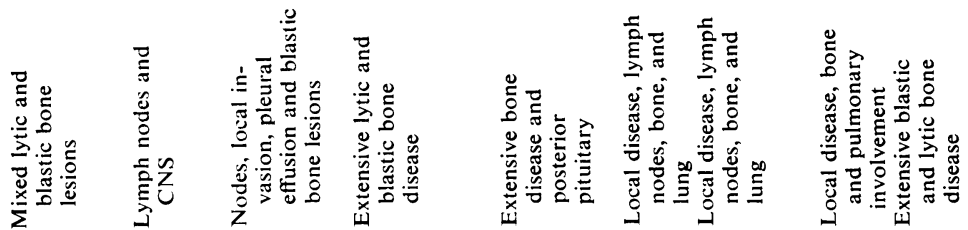
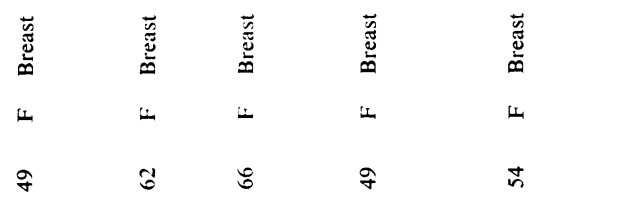

宽

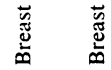

芩

$\therefore \quad$

in

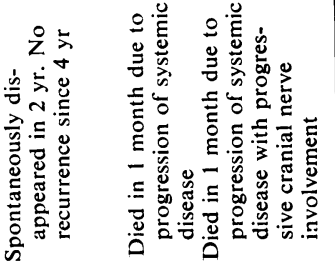

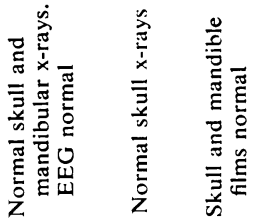

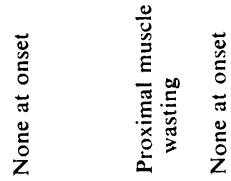

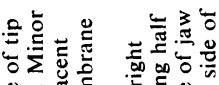

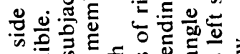

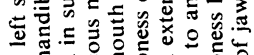

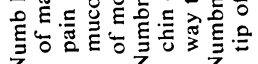

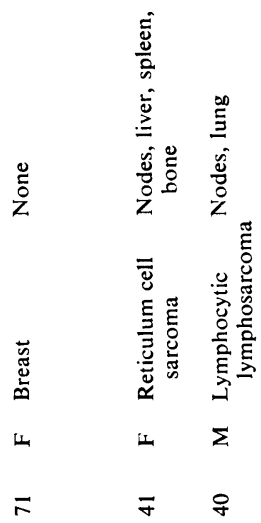




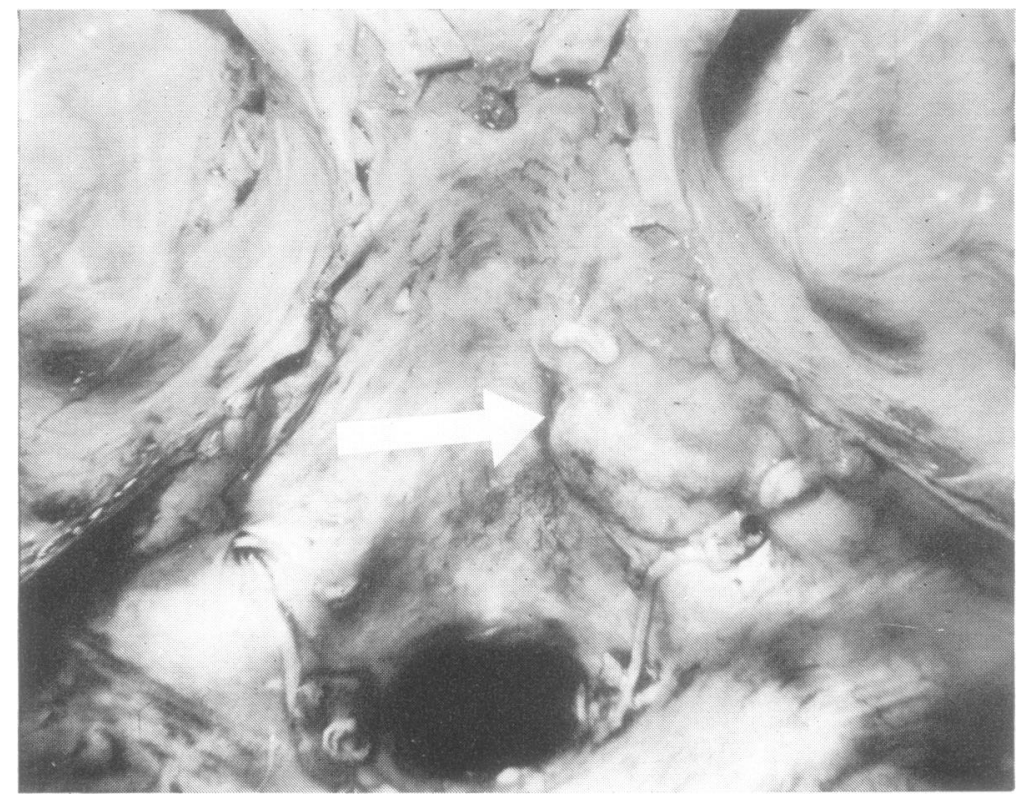

FIG. 1. Demonstrates involvement of the dura mater at the base of the brain of patient no. 3 by tumour metastasis.

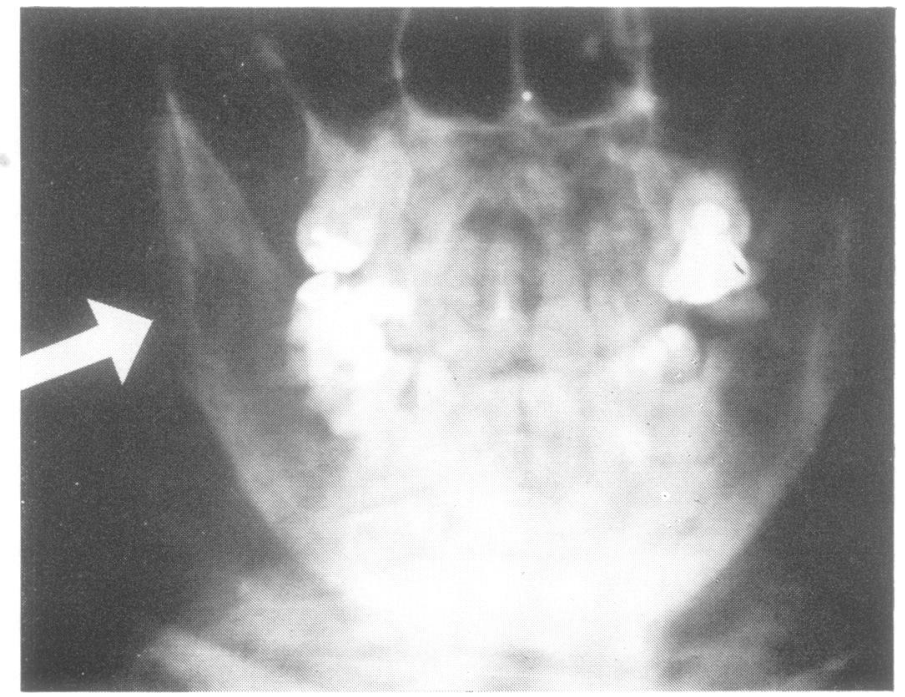

FIG. 2. Arrow points to an area of osteolytic metastasis in the mandible of patient no. 12. 
sion of systemic metastatic disease. The numb chin disappeared only in one patient (no. 13) who had no evidence of metastases and had no antitumour treatment.

Dural involvement by tumour was demonstrated in six of the seven patients who had necropsies. Pathological studies of the mandible were not performed.

\section{DISCUSSION}

We observed unilateral numbness of the chin in $4 \%$ of our patients with breast cancer. Except for the two patients described who had lymphoma, the entity did not occur in patients with other primary sites of tumour. The incidence of parenchymal brain metastasis is higher in lung than in breast cancer at our institution (Horton, Baxter, Olson, and Eastern Cooperative Oncology Group, 1971) but none of the patients with lung cancer have complained of numbness of the chin. Rubinstein (1969) described six patients with numbness of the chin of whom none had breast cancer but four had lymphoma or Hodgkin's disease. The reason for the predilection in our series for breast cancer to cause this symptom is not clear. It parallels, however, our experience with metastases to the posterior pituitary gland (Houck, Olson, and Horton, 1970). There was a preponderance of involvement by breast cancer and, to a lesser degree, lymphoma and leukaemia.

Our findings suggest that a single cause would not satisfactorily explain the symptom in all patients. In the patients who had tumour involving the dura mater at necropsy there seems little doubt that there was interference with the sensory pathway of the trigeminal nerve in the region of the base of the skull where it is encompassed by the dura mater. Direct tumour metastasis to the nerve as described by Barron (Barron, Rowland, and Zimmerman, 1960) may also have played a role in two patients. The radiological evidence of metastatic disease in the mandible in another two patients suggests that there may have been interruption of function of the mental nerve. Both patients, however, had dural metastasis at necropsy. The pathogenesis in four patients with breast cancer whose neurological deficit did not progress is not clear, since none of the three who died came to necropsy. The outcome of one patient, who is still alive with no evidence of metastasis for four years after her symptom developed, raises the possibility of this being a neuropathy unrelated to direct involvement by tumour. It seems unlikely that she represents an example of benign sensory trigeminal neuropathy, since the symptomatology in this syndrome is usually short lived (Hill, 1954).

Four patients received drugs that can cause peripheral neuropathy. Three received vincristine (Sandler, Tobin, and Henderson, 1969) and one 1-acetyl, 2-picolinyl hydrazine (NSC 68626) (Olson, Horton, Pratt, Paladine, Cunningham, Sullivan, Hosley, and Treble, 1969). These drugs tend to produce a symmetrical peripheral polyneuropathy rather than a mononeuropathy and they could not be implicated, since in each case they were given after the symptom had appeared.

Our experience that the mandibular branch of the trigeminal nerve is peculiarly susceptible to the effects of tumours parallels that of Rubinstein (1969). Of his patients with involvement of the mandibular division the symptoms were most pronounced on the chin and, like ours, there was never any dysfunction of the ophthalmic division or motor branch of the Vth nerve. None of the patients had bilateral symptoms.

The reason for this peculiar predilection for involvement of the mandibular branch of the trigeminal nerve is not clear. The commonly encountered trigeminal sensory abnormality, tic douloureux, characteristically also involves the mandibular and/or the maxillary branch and rarely involves the ophthalmic division (Carney, 1967). Benign sensory trigeminal neuropathy, too, follows this pattern. Mechanical factors have been implicated in the genesis of trigeminal neuralgia (Lindsay, 1969) and may likewise play a part in our patients with numbness of the chin. It is possible that displacement or distortion of the trigeminal nerve or ganglion could have resulted from radiologically undetected contiguous bony metastasis. Spread of tumour to the trigeminal nerve from involved dura mater may have gone undetected, since necropsies were not performed on some of these patients.

\section{REFERENCES}

Ashworth, B., and Tait, G. B. W. (1971). Trigeminal neuropathy in connective tissue disease. Neurology (Minneapolis), 21, 609-614.

Barron, K. D., Rowland, L. P., and Zimmerman, H. M. 
(1960). Neuropathy with malignant tumor metastases. Journal of Nervous and Mental Diseases, 131, 10-31.

Carney, L. R. (1967). Considerations on the cause and treatment of trigeminal neuralgia. Neurology (Minneapolis), 17, 1143-1151.

Collard, P. J., and Hargreaves, W. H. (1947). Neuropathy after stilbamidine. Lancet, 2, 686-688.

Goldstein, N. P., Gibilisco, J. A., and Rushton, J. G. (1963). Trigeminal neuropathy and neuritis. Journal of the American Medical Association, 184, 458-462.

Hill, T. R. (1954). Two cases of trigeminal neuropathy. Proceedings of the Royal Society of Medicine, 47, 914-915.

Horton, J., Baxter, D. H., Olson, K. B., and the Eastern Cooperative Oncology Group (1971). The management of metastases to the brain by irradiation and corticosteroids. American Journal of Roentgenology, Radium Therapy and Nuclear Medicine, 111, 334-336.

Houck, W. A., Olson, K. B., and Horton, J. (1970). Clinical features of tumor metastasis to the pituitary. Cancer, 26, 656-659.

Hughes, B. (1958). Chronic benign trigeminal paresis. Proceedings of the Society of Medicine, 51, 529-531.

Jefferson, M. (1957). Sarcoidosis of the nervous system. Brain, 80, 540-556.
Lindsay, B. (1969). Trigeminal neuralgia: A new approach. Medical Journal of Australia, 1, 8-13.

McAlpine, D., Lumsden, C. E., and Acheson, E. D. (1965). Multiple Sclerosis, A Reappraisal, p. 121. Livingstone: Edinburgh.

Mitchell, A. B. S., and Parsons-Smith, B. G. (1969). Trichloroethylene neuropathy. British Medical Journal, 1, 422-423.

New, G. B. (1922). Syndrome of malignant tumors of the nasopharynx. Journal of the American Medical Association, $\overrightarrow{\vec{F}}$ 79, 10-14.

Olson, K. B., Horton, J., Pratt, K. L., Paladine, W. J., Jr., Cunningham, T., Sullivan, J., Hosley, H., and Treble, D. H. (1969). 1-Acetyl-2-picolinoylhydrazine (NSC68626) in the treatment of advanced cancer. Cancer Chemotherapy Reports, 53, 291-296.

Ornsteen, A. M. (1931). Isolated bilateral trigeminal nerve disease presumably syphilitic in origin. Journal of Nervous and Mental Disease, 74, 297-300.

Rubinstein, M. K. (1969). Cranial mononeuropathy as the first sign of intracranial metastases. Annals of Internal Medicine, 70, 49-54.

Sandler, S. G., Tobin, W., and Henderson, E. S. (1969). Vincristine-induced neuropathy. A clinical study of fifty leukemic patients. Neurology (Minneapolis), 19, 367-374. 